\title{
Nuestras puertas están abiertas
}

Durante la transición entre dos comisiones directivas, se generan algunos desafíos como los de continuar los proyectos en curso e impulsar las nuevas prioridades de la comisión entrante. Muchas veces los proyectos y prioridades son diferentes, lo que puede generar ineficiencia en el uso de los recursos y pérdida del trabajo realizado por quienes dedicaron dos años a esta noble causa. Por este motivo, la Comisión Directiva entrante ha decidido continuar con los proyectos ya iniciados y desarrollar nuevas líneas de trabajo.

Describiremos brevemente algunos de los nuevos proyectos, el estado de situación de los heredados de la comisión anterior y finalmente abordaremos el tema de la digitalización e informatización de la Sociedad Uruguaya de Cardiología (SUC).

Proyectos nuevos que pretendemos se constituyan en el buque insignia del año 2020:

\section{Recertificación en Cardiología}

Creemos que la recertificación es una prioridad para asegurar la formación continua y mejorar la atención de los pacientes. Es por este motivo que se invitó a los Dres. Bernardo Layerle y Washington Vignolo a coordinar su implementación. El programa tendrá como objetivo certificar a los cardiólogos mediante la acumulación de puntos o créditos, durante un período a definir. La SUC generará de esta forma un registro de cardiólogos recertificados, el cual estará disponible para consulta en la web institucional de la sociedad. Está programado presentar el Programa de Recertificación en el 36º Congreso Uruguayo de Cardiología y ejecutarlo en el año 2021.

\section{Incrementar ingresos}

Con respecto a este tema, proponemos elaborar un plan para aumentar el usufructo del "sello de certificación SUC", el cual representa un gran valor para la sociedad. Es nuestra intención tomar una actitud proactiva al respecto con el objetivo de incorporar más empresas y productos certificados por la SUC, y de esta forma, aumentar los ingresos.

Dentro de los objetivos 2019, la sociedad planteó la remodelación del área posterior de la sede, con la intención de construir un salón multipropósito para ser utilizado en actividades de educación médica y eventos sociales. Se exploraron diversas alternativas para su financiación, entre las que destacan el uso de fondos propios, aportes de la industria, donaciones y eventualmente el aumento transitorio de la cuota social. El aporte de donaciones fue escaso, por lo cual se rediseñará una estrategia para su estímulo. Está planeado para este año definir el esquema final de financiación y el inicio de tan esperada obra.

También en 2019 se impulsó el Registro de Ecocardiografistas, certificado por la SUC, en el cual se incluyen de forma prospectiva todos aquellos profesionales que certifiquen un mínimo indispensable de requerimientos para el ejercicio de la técnica (establecidos por el Comité de Imagenología). Este registro también será publicado en la web institucional de la sociedad para su consulta.

El 2020 verá materializarse otros dos proyectos impulsados desde directivas anteriores: el proceso de digitalización de la SUC y la reforma del proceso editorial de la Revista Uruguaya de Cardiología (RUC). El nuevo formato de la página web será visible al público en marzo de este año. Respecto a la RUC, también en marzo, se publicará el primer número del Dr. Gerardo Soca como Editor jefe. De sobrados méritos y capacidad laboral, nuestro colega toma el relevo de la Dra. María del Pilar Aguilar, a quien felicitamos y agradecemos por su gran dedicación y gestión, a cargo de tan laboriosa tarea durante los años previos. Ambos editores, junto con los demás prestigiosos integrantes del Consejo Editorial, han trabajado de forma intensa durante 2019 para continuar con el cumplimiento de los requisitos de SciELO. Este paso consiste en la sistematización informática del proceso editorial a través de la plataforma OJS. La experiencia de autores y editores será sustancialmente mejorada, acortando los tiempos y acrecentando la eficiencia del proceso. 
Otros cambios destacados son el cese de impresión de la revista y su publicación online, que ha sido exponencialmente amplificada por su promoción a través de medios digitales, determinando una mayor llegada al público objetivo.

Desde este momento invitamos a todos nuestros socios que tengan sugerencias o reclamos en cuanto a gestión y proyectos, a acercarse a la sociedad tanto de forma presencial como por correo electrónico.

Nuestras puertas están abiertas.

Dr. Víctor Dayan

Presidente de la Sociedad Uruguaya de Cardiología

Víctor Dayan, https://orcid.org/0000-0002-5470-0585

Este artículo fue aceptado para su publicación por: Editor jefe Dr. Gerardo Soca 